\title{
An analysis of ASHA Facilitator Model: Assam, India
}

\author{
Heikrujam Nongyai Nongdrenkhomba ${ }^{1}$, Banuru Muralidhara Prasad ${ }^{2}$, Achyut ChandraBaishya $^{3}$, \\ Biraj Kanti Shome 4 \\ ${ }^{1,4}$ Regional Coordinator, Community Mobilization, RRC-NE, MOHFW, Guwahati; ${ }^{2}$ Technical Officer, The International Union \\ Against Tuberculosis and Lung Diseases, New Delhi; ${ }^{3}$ Director, RRC-NE, MOHFW, Guwahati, and Professor, Preventive and \\ Social Medicine, Guwahati Medical College, Assam, India.
}

\begin{abstract}
Community Health Worker (CHW) models have evolved as a key community engagement strategy in healthcare. 'Accredited Social Health Activist' (ASHA), is a CHW model, implemented to facilitate the process of community engagement in India under the National Rural Health Mission (NRHM). To support ASHAs, a 'supervisory' structure is established, known as 'ASHA Facilitator'. This structure is an amalgamation of various globally known models of supervision. Evidence suggests that the model of supervision is evolving and needs to have an understanding about interlink between community-program-health system. This study aims to analyze the programmatic and community role of ASHA Facilitators within the structure of existing models of supervision. The model of ASHA Facilitators encompasses the supervisory role to ensure service delivery and to monitor activities in relation to restorative, leadership and administrative support. A total of 291 ASHA Facilitators were selected for interview through a stratified random sample method from six districts of Assam, India representing six different regions/zones of the state. It was noted that programmatic roles were performed by ASHA volunteers as per guidelines; however, constrains were noticed in areas of authority and technicalities of program management. As a result, incentive-based tasks influenced the overall supportive supervision role of ASHA Facilitators. Non-incentivized roles/activities were performed on informal basis which were outside the mandate of program though essential (e.g. community resource generation activity). The current analysis recommends the strengthening of community health systems or community participatory supervisory systems in harmonization with communityprogram-health system through a more structured approach with a formal mechanism of supervision in order to meet the needs of community at large.
\end{abstract}

Keywords: Community Health Worker, ASHA Facilitator, NRHM, Supervisory model, India.

\section{Introduction}

Community Health Worker (CHW) concept was re-introduced in India to generate demand for seeking health services under National Rural Health Mission (NRHM). ${ }^{1,2}$ The focus of NRHM was to develop strategies and implement activities with an aim to achieve Millennium Development Goals (MDGs). ${ }^{3}$ For example, in relation to maternal and child healthcare, the aim is to identify pregnant women at early stages of pregnancy and refer to nearest public health facility and follow-up through complete episode of delivery and immunization of newborn, infant and children. A strategy was developed to have community engagement activities through CHWs in the form of Accredited Social Health Activist (ASHA). ${ }^{3}$ The ASHA volunteer is selected through a local community selection process for every 1000 populations, who would volunteer to take health services to the door step of the community. ASHA receives an incentive based on the activities she undertakes. $^{3} \quad$ Furthermore to support ASHAs a supervisory support structure (ASHA Facilitator) is established to facilitate workers in their role of community engagement. ${ }^{4}$ An ASHA Facilitator is expected to cover 10 to 20 ASHAs. Through this supportive structure it was intended to improve the performance of ASHAs. 5,6 However, there is limited evidence on the needs of the

\section{Practice Points}

- The ASHA is a CHW model which is being implemented to facilitate the process of community engagement in India under the NRHM.

- To support ASHAs, a 'supervisory' structure is established, known as 'ASHA Facilitators' which is an amalgamation of various globally known models of supervision.

- It was noted that programmatic roles were performed by ASHAs as per guidelines; however, constrains were noticed in areas of authority and technicalities of program management.

- As a result, incentive-based tasks influenced the overall supportive supervision role of ASHA Facilitators. Non-incentivized roles/activities are performed on informal basis, which are outside the mandate of program though essential.

- The current analysis recommends for a more structured approach from an informal to formal mechanisms of supervision to be designed and implemented for better healthcare.

Correspondence: Mr. Heikrujam Nongyai Nongdrenkhomba, Regional Coordinator- Community Mobilization, The Regional Resource Center for North Eastern States, Ministry of Health and Family Welfare (RRC-NE, MOHFW), Guwahati, Assam, India. E-mail: nongyai.h@gmail.com. 
'supervisors' and their skills and challenges encountered in performing such supervisory roles. The paper provides an analysis of supportive supervisory structure implemented to facilitate ASHAs (CHWs) in process of community engagement to increase access to health facilities and services.

\section{Conceptual framework}

Supervision, as a method has evolved to monitor healthcare service delivery and act as support structure to improvise quality of services. ${ }^{7}$ A supervisor is a link between the lowest level staff and the management, who ensure meeting the objectives of the program and addresses the needs of staffs under their supervision. ${ }^{7}$ The researchers/supervisors, who are involved in implementation of NRHM, found that the role of 'supervisor' is often seen or understood as 'fault-finding' rather than being supportive. In practice the difference between Supervisors and Facilitators is difficult to differentiate and could depend on programs/healthcare facility settings. Most of the Facilitators consider their role to be only a supervisor as there is a thin-line of demarcation between the two. It is in this context, a supervisor in role of Facilitator could facilitate an informal learning environment, improvise on interpersonal skills, encourage innovations, appreciation of work etc. ${ }^{8}$ Thus the roles of ASHA Facilitators are seen as 'Supervisors' and Program Managers' at the grass root level.

A number of supervisory models are widely discussed in the literature and the popular models include: Proctor's model, ${ }^{9}$ Heron's model, ${ }^{10}$ Holloway's model ${ }^{11}$ and Powell's model. ${ }^{12}$ The Proctor's model describes normative and formative aspects of supervision. Normative aspect of supervision highlight the administration approach i.e. managing projects, patient safety, assessing and assuring quality of services and enhance practice behavior; and restorative approach i.e. support and assistance to identify solutions to problems in day to day work. Formative aspects include continued education and on the job skill development to enhance knowledge. The Proctor's model has been widely used for assessing clinical supervision. ${ }^{13}$ Heron's model of supervision approach, which is also known as traditional model, includes an authoritative (indicators like perspective, informative and confronting) as well as facilitative (cathartic, catalyst and supportive) structure. ${ }^{13}$

Holloway's model of supervision has systems approach within the context of service delivery. In this model the supervisor needs to have skills that are traditional to supervisory role, like supporting, instructing, evaluating, consulting etc. The Powell's model of supervision is interactive, where there is room for self-awareness and operates on weakness and strengths of the supervisor, and shares power and values of people by caring for them. This model enhances the leadership quality among the community level staff. Other than those described here, there are recently developed models e.g. practice/problem-center supervision and solutionfocused approach which have incorporated the cultural knowledge as a core component along with the clinical knowledge. $^{14,15}$
ASHA Facilitators model of the NRHM is an amalgamation of models described above guiding towards a 'supportive supervision'. ${ }^{16}$ The structural model evolved over time in lieu of the various documented experiences of such models in the country (e.g. Parinche; Project of Foundation for Research on Community Health). ${ }^{17}$ As the structure evolved, monitoring of subordinates was the key function, which was later defined into assessing the knowledge, training needs, administrative activities, community response and co-ordination activities, programmatic areas and lately, and leadership role. The structure was thus formulated into a group supervisory type of structure wherein one Facilitator supervises about 10-20 ASHAs and is responsible for the service delivery and program implementation in designated areas.

In this paper, we adopted a survey methodology to capture/validate both quantitative and qualitative data through a structured questionnaire. The quantitative data was utilized for documenting the service delivery components and qualitative data was utilized for analysis of non-service delivery components. The analysis and results are interpreted within the framework where ASHA Facilitator is ensuring service delivery, monitoring, restorative (on job training), leadership (community mobilization), and administration.

\section{Materials and methods}

The study was conducted in Assam, a North-Eastern state of India, from February to March, 2011 by the Regional Resource Centre for North Eastern States (RRC-NE). The RRC-NE is a technical support institution under Ministry of Health and Family Welfare, Government of India which is responsible for technical assistance to the North Eastern States of India for implementation of NRHM in the region. In the state of Assam, 28,798 ASHAs were selected and completed the necessary training to provide service to 31 million population (river and hilly terrain). As the part of supportive structure 2,700 ASHA Facilitators are selected and trained to engage at block level $(80,000$ to 150,000 populations).

\section{Sampling}

A systematic random and population proportionate sampling survey method was used to select ASHA Facilitators. Of the 2700 ASHA Facilitators in the State of Assam, 859 Facilitators belong to the six out of 27 districts were selected for the study. The districts were selected based on their performance and from six geographic locations. Following this health facility (primary health center) wise line-listing of ASHA Facilitators was done alphabetically. Assigning the sample interval of three; $33 \%$ i.e. one third of the ASHA Facilitators were selected from each block totaling to $33 \%$ of ASHA Facilitators in respective selected six sample districts. From this method, a total of 283 ASHA Facilitators were selected for the interview. In addition, eight best performing ASHA Facilitators from the identified districts were included for the interview. 
ASHA Facilitators were interviewed through a consultative process using a pre-tested questionnaire tool specifically designed for this study. Following finalization, investigators were selected and trained on how to administer the questionnaire. The investigators conducted interview with ASHA Facilitator at the respective villages/place of her residence. Interview was conducted during February to March 2011. Consent from ASHA Facilitators was obtained before administering the questionnaire. The interview schedule had qualitative questions, which were open-ended and quantitative questions, which were close-ended. The quantitative responses were analyzed using the SPSS software and qualitative responses were analyzed manually. Institutional ethical committee had reviewed the proposal and provided permission to conduct the survey.

\section{Results}

\section{ASHA Facilitators Model analysis}

\section{i. Age and education status}

ASHA Facilitators interviewed for the study were in the age group of 30-39 years and $49 \%$ of them were graduates. Approximately, a quarter of ASHA Facilitators $(27 \%)$ had prior experience of working in similar roles in local NGOs. Remaining quarter of ASHA Facilitators had performed the role of teachers $(24 \%)$. About 4\% of ASHA Facilitators were earlier working as ASHAs. This 4\% selection is the promoted from ASHAs to ASHA Facilitator recognition of their contribution and performance in taking health care to the community.

\section{ii. Community reach}

The program design assigns the responsibility to ASHA Facilitators to supervise about 10-20 ASHAs. Accordingly, in the sample, ASHA Facilitators on an average supervise about 10-14 ASHAs (62\%) (Table 1). A few ASHA Facilitators (36\%) during the interview accepted that they supervise less than 10 in number of ASHAs.

Secondly, a Facilitator has to make a tour plan of 20day field visit and approximately $85 \%$ reported to have adhered to the guidelines. However, $11 \%$ of them made visit ranging from 15 to 19 days (Table 2). In order to make these field visits, a Facilitator on an average had travelled $>10 \mathrm{kms}$ (one way) per visit. However, about 24\% ASHA Facilitators travelled 5-9kms; about 23\% ASHA Facilitators travelled $10-14 \mathrm{kms}$ and $22 \%$ travelled $>20 \mathrm{kms}$ to reach to the farthest ASHAs and/or the village to monitor/validate the activities conducted. In order to make these visits, ASHA Facilitators depended on public transport and at many instances they have travelled 'on foot' to reach ASHAs. During the interview, ASHA Facilitators expressed difficult terrain and lack of local transport facility as reasons for not reaching to all ASHAs.

\section{Analysis of ASHA Facilitator's role}

\section{i. Health Service Indicators}

The NRHM envisaged engaging communities to generate demand for health services through ASHAs. Therefore key role of ASHA Facilitator is to provide supportive supervision in the process of early detection of pregnancy and pregnancy-related complications (bleeding, anemia etc.), newborn health (breast feeding, nutrition, fever detection etc.), mobilize mothers for immunization of children, promoting family planning services, and educating about hygiene practices (hand washing). This also includes treatment for tuberculosis cases and ensures bed-nets distribution for households in malaria endemic areas. About $85 \%$ of ASHA Facilitators felt that the institutional delivery showed continuous improvement following implementation of

Table 1: Number of ASHAs reached by ASHA Facilitators

\begin{tabular}{|l|c|c|c|c|}
\hline Districts & $\begin{array}{c}\mathbf{1 0} \text { ASHA } \\
\text { Facilitators }\end{array}$ & $\begin{array}{c}\mathbf{1 0} \text { to 14 ASHA } \\
\text { Facilitators }\end{array}$ & $\begin{array}{c}\text { >15 ASHA } \\
\text { Facilitators }\end{array}$ & $\begin{array}{c}\text { Total } \\
\text { (Facilitators) }\end{array}$ \\
\hline Cachar & $21(38.18 \%)$ & $34(61.82 \%)$ & 0 & 55 \\
\hline Dhemaji & $4(16.67 \%)$ & $20(83.33 \%)$ & 0 & 24 \\
\hline Dhubri & $20(38.46 \% 0$ & $32(61.54 \%)$ & 0 & 52 \\
\hline Kamrup & $9(17.65 \%)$ & $42(82.35 \%)$ & 0 & 51 \\
\hline Nagaon & $41(60.29 \%)$ & $25(36.76 \%)$ & $2(2.94 \%)$ & 68 \\
\hline Tinsukia & $12(29.27 \%)$ & $27(65.85 \%)$ & $2(4.88 \%)$ & 41 \\
\hline Total & $107(36.77 \%)$ & $180(61.86 \%)$ & $4(1.37 \%)$ & 291 \\
\hline
\end{tabular}

Table 2: Community visits by ASHA Facilitators

\begin{tabular}{|l|c|c|c|c|}
\hline Districts & $<\mathbf{1 5}$ days & $\mathbf{1 5}$ to $\mathbf{1 9}$ days & $\mathbf{2 0}$ days & $\begin{array}{c}\text { Total } \\
\text { (Facilitators) }\end{array}$ \\
\hline Cachar & $3(5.4 \%)$ & $10(18.1 \%)$ & $42(76.3 \%)$ & 55 \\
\hline Dhemaji & 0 & 0 & $24(100 \%)$ & 24 \\
\hline Dhubri & $3(5.7 \%)$ & $18(34.6 \%)$ & $31(59.6 \%)$ & 52 \\
\hline Kamrup & $2(3.9 \%)$ & $1(1.9 \%)$ & $48(94.1 \%)$ & 51 \\
\hline Nagaon & 0 & $5(7.3 \%)$ & $63(92.6 \%)$ & 41 \\
\hline Tinsukia & 0 & 0 & $41(100 \%)$ & 291 \\
\hline Total & $8(2.7 \%)$ & $34(11.6 \%)$ & $249(85.5 \%)$ & \\
\hline
\end{tabular}


community engagement strategies. Along with this, $64 \%$ reported to have observed an increase in number of people adopting family planning methods (both temporary and permanent). ASHA Facilitators (56\%) strongly believed that there has been decline in cases of infant and child deaths and also recorded a decrease in maternal death cases ( $47 \%$ of Facilitators) (Table 3 ).

\section{ii. Monitoring}

ASHA Facilitators monitor the performance of ASHAs against targets, triangulate the data, and interact with beneficiary as outlined in the program. They are also obliged to provide on the job in the for of training and explanation to ASHAs regarding any information about NRHM program. More often as much as $60 \%$ of visits by ASHA Facilitators to field sites of ASHAs were related to trouble shooting, negotiating between health system, community and other community-based health workers. The researchers could not draw upon the percentages of data triangulation errors from ASHA Facilitators' dairy. Moreover, ASHA Facilitators were trained to do such investigation. However, reports available for activities being conducted and incentive were not provided.

\section{iii. Restorative}

ASHA Facilitator's role of restorative is mainly from programmatic aspects and less on the core technical aspect of reproductive, maternal and child health. More than $50 \%$ informed their limitations to provide technical support and requested for additional training. Facilitators are trained over a period of 3-5 days duration and in these training key programmatic requirements, component under the NRHM, recording/ reporting and the core technical requirement related to reproductive, maternal and child health were covered. On contrary to ASHA Facilitators, ASHAs were trained for about 23 days on maternal and child health, disease control programs which include technical as well as programmatic requirements. Thirteen ASHA Facilitators, who were promoted from ASHAs, provided technical support due to their prior exposure to ASHA training. Among other restorative functions, $27.6 \%$ ASHA Facilitators were involved in ensuring payment of incentive to ASHAs. Ensuring the availability of drugs and re-filling the drug kits of respective ASHAs was another major activity performed by Facilitators.

iv. Leadership

ASHA Facilitators faced the challenges of assuming the role of leadership as described by many during the interview schedule which was captured qualitatively. ${ }^{18}$ Role has been more oriented towards bureaucratic process followed by the system rather than of the community.

Facilitators as leader in the community were able to mobilize local authorities for meeting and co-ordinate community led activities from the identified facilities of public health system. On an average $90 \%$ of ASHA Facilitators interviewed highlighted to have performed this role and assumed onus of community's health. Almost all ASHA Facilitators co-ordinate the community led activities of health facilities. As leaders and supervisors to ASHAs, ASHA Facilitators acceptance among ASHAs was also very high with exceptions to those who were promoted from ASHAs.

\section{iv. Administrative}

Administration is part of the functionality of supportive supervision. The supervisors validate records maintained by ASHAs and suggest corrective measures during their community-reach activities. The information about activities performed by each ASHA is updated through a formal process of documentation and reported at their respective designated health facilities, e.g. number of community meetings organized, decisions taken etc. These are validated by ASHA Facilitator and reported to health facility.

The analysis of reports submitted to health facility revealed that almost all ASHA Facilitators had requested for timely release of incentives to ASHAs. This was also an observation made by Program Managers at health facilities. Model per se does not provide any administrative powers to Facilitators; as a result the role of ASHA Facilitators is determined only by release of incentives to ASHAs. Many of the non-incentive based activities are not recorded by ASHA Facilitators as these are not required by the program, for example, community mobilization for resource generation for support of travel of sick patients from the villages to higher health facilities at the district headquarters.

\section{Discussion}

Community healthcare worker models are implemented to enhance community engagement strategies in developed and developing countries. ${ }^{19}$ The models implemented are tailored to meet the community needs at village settings. In India, CHW/Village Health Guide

Table 3: Perceptive changes in health service indicators as reported by ASHA Facilitators

\begin{tabular}{|l|c|c|c|c|c|}
\hline Districts & $\begin{array}{c}\text { Anstitutional } \\
\text { delivery }\end{array}$ & $\begin{array}{c}\downarrow \text { Child/newborn } \\
\text { death }\end{array}$ & $\begin{array}{c}\text { 个Family } \\
\text { planning }\end{array}$ & $\begin{array}{c}\downarrow \text { Maternal } \\
\text { death }\end{array}$ & 个Immunization \\
\hline Cachar & $44(80 \%)$ & $21(38 \%)$ & $40(72 \%)$ & $29(52 \%)$ & $26(47 \%)$ \\
\hline Dhemaji & $19(79 \%)$ & $22(91 \%)$ & $18(75 \%)$ & $16(66 \%)$ & $1(4 \%)$ \\
\hline Dhubri & $41(78 \%)$ & $30(57 \%)$ & $34(65 \%)$ & $24(46 \%)$ & $4(7 \%)$ \\
\hline Kamrup & $43(84 \%)$ & $21(41 \%)$ & $27(52 \%)$ & $19(37 \%)$ & $10(19 \%)$ \\
\hline Nagaon & $62(91 \%)$ & $46(67 \%)$ & $37(54 \%)$ & $40(58 \%)$ & $1(1 \%)$ \\
\hline Tinsukia & $40(97 \%)$ & $25(60 \%)$ & $32(78 \%)$ & $10(24 \%)$ & 0 \\
\hline Total & $249(85 \%)$ & $165(56 \%)$ & $188(64 \%)$ & $138(47 \%)$ & $42(14 \%)$ \\
\hline
\end{tabular}

South East Asia Journal of Public Health 2013;3(2):41-46 
(VHG) scheme was introduced in 1981 and was discontinued in 2005 due to poor programmatic output and also following lack of budgetary allocations to the scheme. $^{20}$ The CHW concept was re-introduced as ASHA under the NRHM in 2005, drawing from the experiences of implementing the VHG scheme. ${ }^{21}$ The current model is aimed at a holistic approach of health and social development; however, activities linked to incentives are on priority and less on program/ supportive structure.

The current study outlines ASHA Facilitator supervisory structure and relate to existing 'supervisory' models. On an average in this study, each supervisor supervises about 10-14 ASHAs. There is limited literature on the requisite number of subordinates a supervisor could supervise. This could also depend on the nature of sector and degree of supervision needed. The supervisory visits are essential part of the clinical model. In this study the number of supervisory visits varies in comparison to requisites outlined in program. It is known that continued supervisory visits are essential for improving the performance. ${ }^{22}$ About 50\% revealed their limitation to provide technical support due to lack of adequate training (only 3 to 5 days training) and this could have implications on leadership role and problem solving. The models need to incorporate the strategies of continuous training or refresher training for ASHA Facilitators. The same has was suggested by kim et al. ${ }^{23}$ where they found that the duration of training was directly proportional to facilitative and informative communication.

During the supervisory visits, ASHA Facilitators are taking up consultative, and counseling as well as administrative tasks which could be related to Proctor model. ${ }^{9}$ Document verification and proposal for payment to ASHAs is one of the key administrative roles that is assumed by ASHA Facilitators. The CHW model operates on voluntary basis and there is always the "power struggle' to link between health system and community volunteers in expediting the administrative role. The supervisory task by health systems personnel performed is more of authoritative and administrative. However, when community performs the supervisory role, it would be more of participative approach. Evidence show that community participatory supervision has produced better results. ${ }^{24}$ Panchayati-Raj institutions (community monitoring structure) conduct supervision of ASHAs and highlighted that increase involvement increased the utilization of budget as well as community contributions.

ASHA Facilitators in this study are taking the role of supervisors as described in Holloways model ${ }^{11}$; however, ASHAs who were earlier working as ASHA before getting selected as ASHA Facilitators are facing the challenge of acceptance from their fellow ASHAs. This also draws attention of the policy makers to visualize the career growth for ASHAs. While the policy makers are reviewing and re-defining the models, one such model could be the ' 7 Eyed Supervision Model' developed by Hawkins \& Shohet. ${ }^{25}$ Our study highlight the need for more structured approach to develop models of supervision as the results direct towards an amalgamation of existing models. However, the present study did not emphasize on the other community based health workers who are also part of the supervisory structure as described elsewhere. ${ }^{18}$

\section{Conclusion}

The sustainability of community healthcare worker models could be related to existence of support or supervisory structures/system. The ASHA Facilitator model of India demonstrates the need for such structures for sustainability of the CHW models globally to link community-program-system. The current model of ASHA Facilitator didn't consider the existing models of supervision and therefore relating to theoretical model would not be justifiable. However, the programmatic aspect of facilitator model is evolving and as the program advances, newer strategies are designed for effective implementation. This draws upon the theoretical approaches to supportive supervision to visualize the ASHA Facilitator model of India as one of overarching models for designing community supervisory structure. The current analysis recommends for a more structured approach from an informal to formal mechanisms of supervision to be designed and implemented for better healthcare.

\section{Acknowledgement}

The authors like to thanks the ASHA Facilitators and authorities of public health facilities for providing their valuable time to complete the research.

\section{References}

1. The Planning Commission of India. Sixth Five Year Plan (1980-85). Chapter 22: Health Family Planning and Nutrition. New Delhi: The Planning Commission of India, 1981.

2. The Planning Commission of India. Mid-term appraisal of Tenth Five Year Plan (2002-2007). Part two Sectoral and other issues. Chapter 2: Human Development -Health, Family Welfare and Nutrition. New Delhi: The Planning Commission of India, 2005.

3. The Planning Commission of India. National Rural Health Mission: Framework for Implementation, Ministry of Health and Family Welfare. New Delhi: The Planning Commission of India, 2005.

4. The Planning Commission of India. Eleventh Five Year Plan 2007-2012, Vol. II - Social Sector. New Delhi: The Planning Commission of India, 2007.

5. Bhattacharji S, Abraham S, Muliyil JP, Job JS, Jhon KR, Joseph AA. Evaluating community health worker performance in India. Health Policy Plann 1986; 1:232-9.

6. Curtale F, Siwakoti B, Lagrosa C, LaRaja M, 
Guerra R. Improving skills and utilization of community health volunteers in Nepal. Soc Sci Med 1995; 40:1117-25.

7. Lani M, Linda K. Making Supervision supportive and Sustainable: New Approaches to Old Problems. In MAQ Papers. Global: Management Sciences for Health, Washington, DC, 2002.

8. Christina M: The supervisor as a facilitator of informal learning in work teams. $J$ Workplace Learn 2001; 12:246-53.

9. Sloan G, Watson H. Clinical supervision models for nursing: structure, research and limitations. Nursing Standard 2002;17(4):41-6.

10. Heron J. Helping the Client: A Creative Practical Guide. London: Sage Publications, 1990.

11. Holloway EL. Clinical Supervision - A Systems Approach. Thousand Oaks, CA: Sage Publications, 1995

12. Powell DJ. Clinical supervision in Alcohol and Drug Abuse Counselling: Principles, Models, Methods. New Jersey: Jossey-Bass, 2004.

13. Kim YM, Figueroa ME, Martin A, Silva R, Acosta SF, Hurtado M, et al. Participatory Supervision with Provider Self-Assessment Improves Doctor-Patient Communication in Rural Mexico. Operations Research Results 2 (12). Bethesda, MD: Quality Assurance Project, 2002.

14. Fowler J. Solution-focused techniques in clinical supervision. Nurse Times 2007;103(22):30-1.

15. McKenna B, Thom K, Howard F, Williams V. Professional supervision for mental health and addiction nurses: A review of current approaches to professional supervision internationally and in the New Zealand mental health and addiction sector. Auckland: TePou o TeWhakaaro Nui, the National Centre of Mental Health Research, Information and Workforce Development, 2008.

16. Clements CJ, Streefland PH, Malau C. Supervi- sion in primary health care - can it be carried out effectively in developing countries? Curr Drug Saf 2007;2(1):19-23.

17. Antia NH, Bhatia K. NGO Experiences: Implications for health services at the community level. In: FRCH (Ed.), People's health in people's hands. Mumbai: Foundation for Research in Community Health, 1993.

18. Bajpai $\mathrm{N}$, Dholakia RH. Improving the performance of Accredited Social Health Activists in India. In Working Paper Series. Mumbai: Columbia Global Centers, 2011.

19. Prasad BM, Muraleedharan VR. Community health workers: a review of concepts, practice and policy concerns. London: Department for International Development (DFID), 2008.

20. UNICEF. What works for children in south Asia- Community health workers? Kathmandu: United Nations Children's Fund, 2004.

21. Gosavi SV, Raut AV, Deshmukh PR, Mehendale AM, Garg BS. ASHAs awareness and perceptions about their roles and responsibilities: A study from rural Wardha. J Mahatma Gandhi Institute Med Sci 2011; 1(16)

22. Kim YM, Tavrow P, Malianga L, Simba S, Phiri A, and Gumbo P. The quality of supervisorprovider interactions in Zimbabwe. Operations Research Results 1(5). Bethesda, MD: Quality Assurance Project, 2000.

23. Kim YM, Putjuk F, Basuki E, Kols A. SelfAssessment and Peer Review: Improving Indonesian Service Providers' Communication with Clients. Int Fam Plan Perspect 2000;26(1):4-12.

24. Ministry of Public Health. Evaluation of Participatory Model of Supervision in Thailand. Bangkok: Ministry of Public Health, Thailand, 1999.

25. Hawkins P, Shohet R. Supervision in the Helping Professions. $3^{\text {rd }}$ edition. Buckingham Open University Press, 2007. 